\title{
EFEITOS DE UMA DOENÇA CRÔNICA NO BRASIL, MUITO ALÉM DA PANDEMIA
}

\section{EFFECTS OF A CHRONIC DISEASE IN BRAZIL, BEYOND THE PANDEMIC}

\section{RIBEIRO, Thales de Medeiros}

Doutor em Linguística pela Universidade Estadual de Campinas (UNICAMP).

Pós-Doutorando na Faculdade de Filosofia, Ciências e Letras de Ribeirão Preto da Universidade de São Paulo (FFCLRP/USP).

E-mail: thalesmedeirosribeiro@gmail.com

ORCID ID: https://orcid.org/0000-0002-0005-133X

\section{SOUSA, Lucília Maria Abrahão}

Livre-Docente em Ciência da Informação pela Faculdade de Filosofia, Ciências e Letras de Ribeirão Preto da Universidade de São Paulo (FFCLRP/USP). Doutora em Psicologia pela USP.

Professora Associada na Faculdade de Filosofia, Ciências e Letras de Ribeirão Preto da Universidade de São Paulo (FFCLRP/USP).

E-mail: luciliamasousa@gmail.com

ORCID ID: https://orcid.org/0000-0002-4585-9287

\section{RESUMO}

O terror contemporâneo resulta da mutação, sucessão e combinação de diferentes formas de governabilidade. Para abordá-las a partir das discussões de Althusser, Foucault e Mbembe, destacamos a relação entre o Estado e o uso generalizado da violência. À luz da análise de discurso de linha francesa, analisamos como tal associação é enunciada em um documentário jornalístico sobre a escalada da repressão policial nas periferias brasileiras durante a pandemia e em outros materiais ligados ao caso João Pedro, o assassinato de um jovem negro durante uma operação policial em São Gonçalo (RJ).

Palavras-chave: análise do discurso; governabilidade; racismo; violência.

\section{ABSTRACT}

Contemporary terror results from the mutation, succession, and combination of different forms of governance. This article highlights the relationship between the State and the widespread use of violence based on texts by Althusser, Foucault, and Mbembe. In the light of 
the French discourse analysis, we analyzed how such an association is enunciated in a journalistic documentary about the escalation of police repression in the Brazilian peripheries during the pandemic and other materials related to the João Pedro case, the murder of a young black man during a police operation in São Gonçalo (RJ).

Keywords: discourse analysis; governance; racism; violence.

\section{CONSIDERAÇÕES INICIAIS}

Presa em um cerco de injustiça e desigualdade, boa parte da humanidade está ameaçada pela grande asfixia, e a sensação de que nosso mundo está suspenso não para de se espalhar. (MBEMBE, 2020a, n.p.).

O terror que hoje asfixia nossa vida cotidiana não se aparta do poder político' ${ }^{1}$. Ele resulta da mutação, sucessão e combinação de múltiplas formas de governabilidade, como a repressão, a disciplina, o biopoder e a necropolítica. Para abordá-las, um caminho "clássico" seria partir de uma questão eminentemente filosófica, a da querela entre a teoria marxista-leninista e a genealogia nietzschiana, a propósito de como distintas concepções do poder se desdobraram nas obras de Louis Althusser e Michel Foucault². Situada no solo do materialismo histórico, a análise do discurso de linha francesa já releva o embate tenso e contraditório entre essas teorias desde seus textos fundadores, ainda que a discussão seja sempre renovada por leituras atuais sobre as relações entre vida, morte, direito e Estado ${ }^{3}$. Não adentraremos nessa discussão teórica já bastante consolidada. Sobrevoando as contribuições desses dois filósofos, desejamos apenas pontuar a existência de um pacto entre o uso generalizado da violência (policial) e o domínio do poder político. Quer seja detido por uma classe dominante, quer seja exercido em uma rede complexa de relações de força, as duas interpretações do poder apontam para um funcionamento que ultrapassa a repressão e seu caráter coercitivo ("Sobre o Estado: repressão, violência e morte"). Em sequência, pontuamos como a repressão e a violência são atravessadas por problemáticas raciais e coloniais ("O racismo como tecnologia do

\footnotetext{
1 Não nos referimos apenas à pandemia do novo coronavírus que dizimou quase 450 mil brasileiros até o momento em que finalizamos este texto. Escrevemos também sobre (e sob o impacto de) uma política de morte, como a que recentemente se abateu sobre a favela do Jacarezinho, no Rio de Janeiro.

2 Cf. "The soul is the prison of the body", de Montag (1995).

3 Cf. as teses "Você matou meu filho" e outros gritos: um estudo das formas da denúncia, de Modesto (2018), e Entre a escrita e o olhar: uma poética da violência, de Chaves (2020).
} 
Estado"). Por fim, discutimos como a ligação entre violência e Estado é textualizada em materiais ligados ao caso João Pedro ("O rosto de uma guerra sem fim").

\section{SOBRE O ESTADO: REPRESSÃO, VIOLÊNCIA E MORTE}

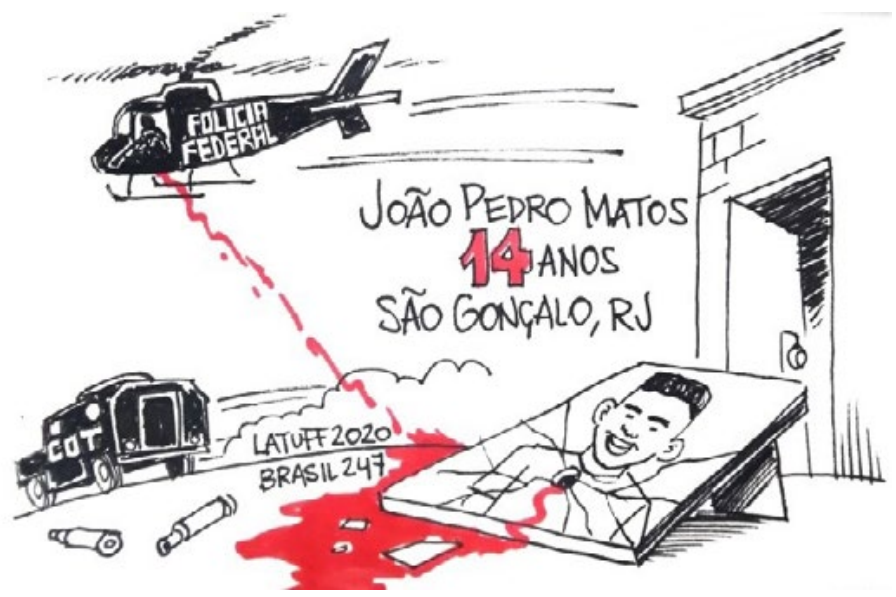

Figura 1: "João Pedro", de Carlos Latuff (19 de maio de 2020).

Fonte: Disponível em: <https://www.brasil247.com/charges/joao-pedro-qmxcbkfn>.

Quando Althusser escreveu sobre o Aparelho Repressivo de Estado (ARE) não poderia imaginar que, em certo momento da história, essa seria a tônica da função do poder. O governo, a administração, o exército, a polícia, os tribunais e as prisões seriam as peças de um aparelho que opera pela violência, seja ela diretamente física ou não (a exemplo das sanções administrativas). ${ }^{4}$ De acordo com o filósofo, o próprio Estado equivale a esse aparelho contaminado por sua força de execução e por sua intervenção repressiva. Ao defini-lo, Althusser pensava na violência usada para conter aqueles os quais os aparelhos ideológicos não teriam conseguido de fato e a termo capturar imaginariamente em um lugar de aceitação do funcionamento social. Fosse na prisão ou no manicômio, a repressão seria a ponta final de uma linha em um grande novelo de interpelações ideológicas tecidas pela escola, família, igreja, mídia dentre outros.

4 Para se avançar na teoria marxista-leninista - argumenta o filósofo -, deve-se considerar uma dupla cisão. Se os "clássicos do marxismo" já distinguiam o poder de Estado de seu aparelho repressivo, há ainda uma outra realidade, diferente da repressão: os Aparelhos Ideológicos do Estado (AIEs). Assim, agir por decretos e leis no aparelho repressivo, por exemplo, não equivale a "agir" pela ideologia dominante no AIE jurídico, ainda que o primeiro crie as condições políticas de exercício do segundo. 
O Aparelho repressivo é compreendido como uma totalidade organizada e centralizada, que funciona de forma prevalente (mas não exclusiva) pela violência, subordinando os membros do Estado a uma "unidade de comando, a da política da luta de classes aplicada pelos representantes políticos das classes dominantes que detêm o poder do Estado" (ALTHUSSER, [1970] 1992, p. 54). Se uma classe (ou aliança de classes) no poder exerce o domínio pela repressão e conserva suas posições fortes nos aparelhos ideológicos, a resistência das classes dominadas sempre pode vir à luz, seja por explorar as contradições desses espaços, seja por conquistar neles certas posições de combate. Para Althusser, não há um aparelho ideológico puro: face à "peste do assujeitamento", a violência ainda está lá, atuando de forma atenuada ou secundária em relação à ideologia.

Contemporaneamente a Ideologia e aparelhos ideológicos do Estado, Foucault lançou o livro que seria reconhecido como um difusor de sua perspectiva genealógica: Vigiar e punir. Para além da hipótese que concebe o poder em sua dimensão repressiva, o autor se voltou ao enlace dos saberes, técnicas e discursos "científicos" com a prática moderna do poder de punir. ${ }^{5}$ Não por acaso, uma das regras gerais de sua escrita era não centralizar a pesquisa sobre os mecanismos punitivos somente "em seus efeitos 'repressivos', só em seu aspecto de 'sanção', mas recolocá-los na série completa dos efeitos positivos [...]. Consequentemente, tomar a punição como uma função social complexa" (FOUCAULT, [1975] 2009, p. 26).

Para o autor, o nascimento da disciplina marcou a dissolução do espetáculo público do suplício. Entre os séculos XVIII e XIX, "desapareceu o corpo supliciado, esquartejado, amputado, marcado simbolicamente no rosto ou no ombro, exposto vivo ou morto, dado como espetáculo. Desapareceu o corpo como alvo principal da repressão penal" (FOUCAULT, [1975] 2009, p. 13). Surgia, assim, uma fórmula geral de dominação dos corpos distinta da escravidão, da domesticidade, da vassalidade e do ascetismo.

Antes das leis que encerravam os suplícios na Europa e nos Estados Unidos, o espaço recortado, imóvel e vigiado da peste formou um primeiro modelo, compacto e excepcional, do dispositivo disciplinar. Sendo uma forma real e imaginária da desordem, a antiga pandemia tinha a disciplina como correlato médico e político: "atrás dos dispositivos

5 Criticando o compromisso de Foucault com a especulação genealógica, Spivak ([1983] 2010, p. 26) considera que tal perspectiva o impediu de situar, nos trabalhos de Marx e Freud, os "divisores de águas de um fluxo contínuo da história intelectual", o que, por consequência, afetou as suas concepções de poder e de repressão. 
disciplinares se lê o terror dos 'contágios', da peste, das revoltas, dos crimes, da vagabundagem, das deserções, das pessoas que aparecem e desaparecem, vivem e morrem na desordem" (FOUCAULT, [1975] 2009, p. 188). Diferentemente do "exílio do leproso" e da "exclusão da loucura", o regime de quarentena e confinamento da peste mostra como o poder se impregna nas mais finas malhas do sujeito, distribuindo-lhes um nome, um lugar, um corpo, uma doença, uma morte e um pertence. A "prisão da peste" planteou os esboços da sociedade moderna, cujo paradigma seriam as casas penitenciárias. Se na visada althusseriana a prisão se enquadra como parte do Aparelho Repressivo de Estado, aqui ela é lida como uma instituição disciplinar, que fabrica "corpos úteis e dóceis" a partir de métodos de "bom adestramento": a vigilância hierárquica, a sanção normalizadora e a combinação de ambos no procedimento do exame.

Após Vigiar e punir, Foucault desenvolveu o conceito de biopoder, tateando uma instância do Estado na qual a repressão e a morte estão postas de modo a serem administradas (FOUCAULT, [1975-1976] 1999; [1976] 1984). ${ }^{6}$ O desaparecimento dos suplícios e a sofisticação das técnicas de vigilância, controle e gestão dos indivíduos deram lugar à proliferação dos campos de concentração e extermínio nos séculos XIX e XX, um nítido projeto de eliminação massiva do "inimigo", reduzido a uma espécie de "perigo biológico" (DELEUZE, [1986] 2005).

No nazismo, a simbólica do sangue (cara à soberania) foi reinvocada para vivificar um novo tipo de poder político: o racismo em sua forma moderna, estatal e biologizante (FOUCAULT, [1976] 1984). O racismo, sem dúvida, não é uma invenção recente, mas ele veio a se inserir como "mecanismo fundamental do poder, tal como se exerce nos Estados modernos, e que faz com que quase não haja funcionamento moderno do Estado que, em certo momento, em certo limite e em certas condições, não passe pelo racismo" (FOUCAULT, [1975-1976] 1999, p. 304).

Em outros termos, o dispositivo de matar e administrar a morte ganha expressão na obra foucaultiana quando ele define o poder não mais

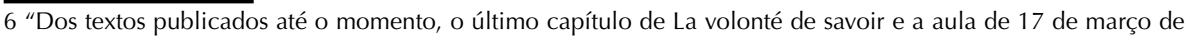
1976 do Curso Il faut défendre la societé devem ser considerados como os textos fundamentais de referência acerca do biopoder. No primeiro, a questão do biopoder aparece em seguida à descrição da formação do dispositivo da sexualidade e termina na questão do racismo moderno, um racismo biológico e de Estado. No segundo, o biopoder aparece ao final de um extenso percurso, no qual Foucault analisa as transformações do conceito de guerra de raças. Em um e no outro, o biopoder se mostra em sua dupla face, como poder sobre a vida (as políticas da vida biológica, entre elas as políticas da sexualidade) e como poder sobre a morte (o racismo)" (CASTRO, 2009, p. 57). 
em termos de confisco, subtração, extorsão, tal como se passava no regime de soberania. Agindo sobre a vida, ele visa ao seu contínuo e incansável melhoramento, multiplicação, incitação [...]. Essa transformação a que a civilização ocidental assistiu não significaria, contudo, o desaparecimento ou neutralização das batalhas e genocídios que a acompanham. Ao contrário [...], os confrontos travados ao longo dos dois últimos séculos testemunham a favor de crueldades sem precedentes. Massacres e extermínios são complementares a um poder que busca aperfeiçoar processos vitais. Se antes guerras eram iniciadas a fim de proteger o soberano, na era do biopoder, a morte de uns assegura a existência de todos [...]. Essa forma de equivaler vida e morte, encontrada na base do biopoder, explica a emergência de fenômenos como o racismo de Estado. (FURTADO; CAMILO, 2016, p. 36).

O Estado nazista que o diga. O direito soberano de matar constituiu a captura ideológica capaz de naturalizar a perseguição de milhares de seres humanos considerados indesejáveis, a execução administrativa na gestão das cidades e o império da logística horrenda dos fornos crematórios e das câmaras de gás. Sobre isso, Semprún afirma que o horror dos campos não pode ser exatamente tocado em seu núcleo mortífero, mas apenas em suas bordas.

O essencial é conseguir superar as evidências do horror para tentar atingir a raiz do Mal radical [...]. O horror era apenas a sua roupagem, o seu adereço, o aparato. A aparência, em suma. Poderíamos passar horas depondo sobre o horror cotidiano sem tocar no essencial da experiência do campo. [...] o essencial não era o horror acumulado, cujas minúcias poderíamos desfiar interminavelmente. Poderíamos contar um dia qualquer, começando pelo despertar às quatro e meia da madrugada, até a hora do toque de recolher: o trabalho estafante, a fome perpétua, a permanente falta de sono, as humilhações dos Kapo, as faxinas de latrinas, a schlague ${ }^{7}$ dos SS, o trabalho em cadeia nas fábricas de armamento, a fumaça do crematório, as execuções públicas, as chamadas intermináveis sob a neve do inverno,

7 "Schlag, 'pancada', em sua versão afrancesada, de schlague, significa 'dar ordens de modo brutal'". 
a exaustão, a morte dos companheiros, sem que por isso tocássemos no essencial, sua obscura verdade fulgurante: a treva que nos coube na partilha. (SEMPRÚN, 1995, p. 92).

Tal experiência da treva partilhada indicia como as palavras faltam diante do modo como esse horror se inscreve na história. Da mesma forma, as "máquinas de guerra" a serviço do horror provam que a desumanização do inimigo não se separa de um processo de industrialização da morte, processo este que articula "a racionalidade instrumental e a racionalidade produtiva e administrativa do mundo moderno (a fábrica, a burocracia, a prisão, o exército). Mecanizada, a execução em série transformou-se em um procedimento puramente técnico, impessoal, silencioso e rápido" (MBEMBE, [2003] 2018, p. 21). Nele, o triunfo funesto da massificação da morte foi um correlato íntimo da disseminação de estereótipos e ideologias racistas, fato que expande nossa discussão sobre os enlaces entre Estado, repressão e racismo.

\section{O RACISMO COMO TECNOLOGIA DO ESTADO}

No célebre ensaio Necropolítica, Achille Mbembe discute o subjugamento da vida a uma formação específica do terror contemporâneo, expondo o Estado em sua dimensão mais violenta. Ele apresenta uma forma de governabilidade diferente do aparelho repressivo e das técnicas disciplinares. Para definir a necropolítica e o necropoder, esse filósofo de base hegeliana explora as zonas fronteiriças do conceito foucaultiano de biopoder com a soberania e com o estado de exceção. O controle sobre a mortalidade traça o limite do poder soberano, que define a vida como implantação e manifestação de seu domínio. Assim como os campos de concentração/extermínio, algumas formas de soberania constituem, ainda hoje, o nomos do espaço político onde habitamos. Nesse espaço, o racismo se infiltra como tecnologia que permite o exercício do biopoder. Em sua economia, esse racismo - larvado ou não - teria por função "regular a distribuição da morte e tornar possíveis as funções assassinas do Estado" (MBEMBE, [2003] 2018, p. 18).

A política da morte se abateu sobre a raça, espectro que assombra as práticas políticas violentas do Ocidente. O Estado nazista talvez tenha sido o exemplo mais completo do direito de matar, pois conjugou três elementos da guerra política: o racismo, o homicídio e o suicídio.

Por uma extrapolação biológica do tema do inimigo político, organizando a guerra contra os seus adversários 
e, ao mesmo tempo, expondo seus próprios cidadãos à guerra, o Estado nazi é visto como aquele que abriu caminho para uma tremenda consolidação do direito de matar, que culminou no projeto da "solução final". Ao fazê-lo, tornou-se o arquétipo de uma formação de poder que combinava as características do Estado racista, Estado assassino e Estado suicidário. (MBEMBE, [2003] 2018, p. 19).

Ao articular a questão racial à colonial, o autor ultrapassa as construções foucaultianas sobre o biopoder. A administração da morte pelo Estado passa a ser endereçada sobretudo a homens e mulheres negros, da plantation e das políticas de colonização empreendidas pela Europa nos séculos passados até as que são adotadas hoje pelo capitalismo neoliberal.

Assim como Althusser demarcou a incipiência de uma correlação direta entre o aparelho repressivo e o domínio público ${ }^{8}, \mathrm{Mbembe}$ constata que a coerção se tornou um produto de mercado, desabando o biombo que separava o público do privado: "milícias urbanas, exércitos privados, exércitos de senhores regionais, segurança privada e exércitos de Estado proclamam, todos, o direito de exercer violência ou matar" (MBEMBE, [2003] 2018, p. 53).

Para Mbembe, qualquer relato histórico sobre a formação do terror moderno deve abordar a escravidão, uma das primeiras manifestações da biopolítica, isto é, da prática de biopoderes locais que, diferentemente do dispositivo disciplinar focalizado nos indivíduos, se centra no controle do território e da população. Sem lar, sem direito sobre o corpo e sem estatuto político, o escravo era dominado e desumanizado pelo senhor, transmutando-se em um instrumento de trabalho (um preço) e uma propriedade (um valor). O domínio absoluto sobre a vida e o corpo do escravo era um ato de pura destruição empregado para aterrá-lo.

Enquanto a plantation impôs a violência como forma de controle social, as colônias sob o regime do apartheid fundaram uma modalidade peculiar do terror. Se há dois princípios chaves da ordem jurídica

8 Em hipótese, o aparelho repressivo do Estado parece pertencer ao domínio público, enquanto a pluralidade de aparelhos ideológicos de Estado às instituições privadas. Contudo, o filósofo marxista considera que o Estado condiciona esses polos, sendo impossível traçar, por meio da oposição público-privado, uma linha divisória que separe repressão e ideologia. "A distinção entre o público e o privado é uma distinção interior ao direito burguês, e válida nos domínios (subordinados) em que o direito burguês exerce os seus 'poderes'. O domínio do Estado escapa-Ihe porque está 'para além do Direito': o Estado, que é o Estado da classe dominante, não é nem público nem privado, é pelo contrário a condição de toda a distinção entre público e privado. Podemos dizer a mesma coisa partindo agora dos nossos Aparelhos ideológicos do Estado. Pouco importa que as instituições que os realizem sejam 'públicas' ou 'privadas'. O que importa é o seu funcionamento. Instituições privadas podem perfeitamente 'funcionar' como Aparelhos Ideológicos do Estado" (ALTHUSSER, [1970] 1992, p. 45-46). 
europeia (igualdade dos Estados e territorialização do Estado soberano), o imaginário colonialista os exclui, concebendo o mundo colonial à imagem das fronteiras. Nelas, figuras internas e externas da política (guerra e desordem) são pareadas ou alternadas. As colônias são o lugar onde as garantias da ordem judicial se encontram suspensas e o direito soberano de matar não segue mais nenhuma regra.

Concatenando o biopoder, o estado de exceção e o estado de sítio, as colônias constituíram uma primeira síntese entre massacre e burocracia. Nesse sentido, não é improvável que os horrores da Segunda Guerra sejam coextensivos a um terror antes reservado ao "mundo colonial".

No fim, pouco importa que as tecnologias que culminaram no nazismo tenham sua origem na plantation ou na colônia, ou, pelo contrário - a tese foucaultiana -, que nazismo e stalinismo não tenham feito mais do que ampliar uma série de mecanismos que já existiam nas formações sociais e políticas da Europa ocidental (subjugação do corpo, regulamentações médicas, darwinismo social, eugenia, teorias médico-legais sobre hereditariedade, degeneração e raça). Um traço persiste evidente: no pensamento filosófico moderno assim como na prática e no imaginário político europeu, a colônia representa o lugar em que a soberania consiste fundamentalmente no exercício de um poder à margem da lei (ab legibus solutus) e no qual a "paz" tende a assumir o rosto de uma "guerra sem fim". (MBEMBE, [2003] 2018, p. 32-33).

Se a soberania define quais vidas importam e quais são "descartáveis", a ocupação colonial tardia combina a disciplina, a biopolítica e a necropolítica. Tal combinação terrificante faz com que o poder colonial se alastre sobre os habitantes do território sitiado, sem distingui-los entre inimigos externos e internos. O terror contemporâneo se ata à fragmentação territorial (terrestre e aérea) na qual os espaços de violência se multiplicam.

Apesar de abordar questões próprias às guerras e ocupações na Palestina, Cisjordânia, África do Sul e Ruanda, a especificidade da formação social brasileira parece se alinhar a essa tese. Além das sanções e do aprisionamento em massa que asseguram o controle dos indivíduos e das populações, novas tecnologias de destruição se voltam cada vez mais ao massacre a céu aberto (que se somam às matanças invisíveis): "o 
terror é uma característica que define tanto os Estados escravistas quanto os regimes coloniais contemporâneos" (MBEMBE, [2003] 2018 p. 68). Eis-nos, portanto, diante da política racista da morte em sua versão mais eruptiva e viral.

O racismo estrutural que empilha os corpos racializados tende a se apresentar como "acidente", mero acaso separado das condições, práticas e dizeres que o condicionam. ${ }^{9} \mathrm{O}$ processo de desumanização dos corpos negros não é exclusivo ao regime da plantation e ainda hoje nos assola. Em 2019, por exemplo, Pedro Henrique Gonzaga foi morto por um segurança dentro do supermercado Extra no Rio de Janeiro. ${ }^{10} \mathrm{~A}$ sua morte provocou uma indignação coletiva, disseminando dizeres em torno do racismo, como a conhecida fórmula "vidas negras importam".

A comoção em torno da morte truculenta de Gonzaga fez emergir a indignação sobre um crime cotidiano no Brasil, o fato da vítima ser um jovem negro. Enunciados como 'vidas negras importam', 'minha cor não é de luto', 'a carne mais barata do mercado é a carne negra' e 'Extra assassino' circularam em cartazes durante atos de protestos nos supermercados da rede Extra, como também nas redes sociais, produzindo sentidos que ultrapassavam a singularidade daquele acontecimento pelas memórias que ele convocava das relações macabras entre homicídio, classe e cor de pele no Brasil. [...] Nessa ocasião, o estatuto do que é concebido como humanidade se colocava a partir da dimensão da comoção em torno da morte e do luto, o que nos mostra que aquilo que entendemos como humano não é tão evidente assim [...]. Isso diz respeito a uma operação de poder que regula afetos e posições éticas definindo por quem somos indiferentes e por quem lamentamos profundamente. [...] A morte de Gonzaga é uma entre tantas que sequer aparecem como contáveis. (CHAVES, 2020, p. 77).

O percurso por essas três reflexões sobre o Estado e a repressão nos leva a pontuar, portanto, que o discurso é uma dimensão inseparável

\footnotetext{
9 Mbembe defendeu esse argumento, rememorando o ataque que vitimou George Floyd há um ano nos Estados Unidos. "O racismo consiste [...] em fazer de toda tragédia que ele provoca um acidente, em inscrever constantemente a vida do sujeito racializado em uma série infinita de acidentes que não cessam de se repetir. Na verdade, esses 'acidentes' fazem sempre parte da estrutura" (MBEMBE, 2020b, n.p.).

10 Outra forma de desumanização ocorreu com a notícia do assassinato de Cláudia da Silva Ferreira. A princípio, ela não era sequer nomeada pela grande mídia, mas apenas designada como "a mulher arrastada" (GARCIA; SOUSA, 2015).
} 
dos processos e dos mecanismos que constituem o terror atual. A seguir, abordaremos como a relação entre a violência e o Estado é discursivizada em um documentário jornalístico e em outros materiais relacionados ao caso João Pedro.

\section{O ROSTO DE UMA GUERRA SEM FIM}

\section{Sujeitos determinados}

Não quero ver o vídeo do homem morrendo

Sob as patas do outro homem

Ainda nem sarei do tiro nas costas

Que deram em João Pedro

Isso vai entristecendo a gente

Até a exaustão

Mas nada comparado

Aos que sentem na pele

Estar sob as patas de outro homem

Aqueles cujas filhas se chamam ágatas

Pedrinhas coloridas que fazem balé

Ou street dance

Meninos que podiam ser

Homens que crescem

Mas há algo que precisa ser dito

A despeito do ritmo da vida

Ou a despeito do ritmo de um poema

Que se não temos coragem de

Colocar fogo nos racistas

Precisamos pelo menos acabar com o

Sujeito indeterminado:

O genocídio da população negra

É autorizado de dentro dos palácios dos governadores

E é executado pelas polícias.

(Adriane Garcia, 2021 [Poemas para fazer o luto desse tempo], p. 24). 
Em janeiro de 2021, a BBC News publicou um documentário sobre a escalada da repressão policial nas periferias brasileiras durante a pandemia. ${ }^{11}$ Após a advertência de que "o vídeo contém imagens e relatos de violência", constrói-se um mosaico com figuras de terror e da revolta, um horror do qual apenas se pode ver as bordas: viaturas, helicópteros, fardas, armas, fragmentos da vida cotidiana de três jovens assassinados, testemunhos de mães recém-enlutadas, clamores por justiça proferidos por manifestantes de vestes (e máscaras) brancas.

A sucessão veloz de cenas, gritos, lamentos e relatos é, então, cortada pela tela de abertura. Nela, um jovem negro nos encara. Impregnado pela coloração cinza azulada do céu, seu rosto se funde e se sobrepõe à visão panorâmica de uma favela do Rio de Janeiro. A faixa preta centralizada dá a ler uma pergunta tão transparente e tão opaca quanto a própria composição material da imagem: a vida dos negros importa no Brasil?

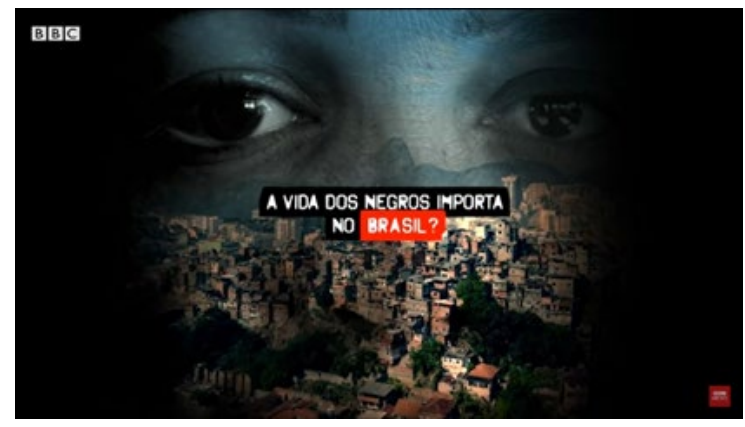

Figura 2: Fotograma de "As histórias por trás de recorde de mortes pela polícia em plena pandemia".

À primeira vista, o enunciado parece perfeitamente familiar, remetendo ao movimento social disseminado após a morte de George Floyd, em 25 de maio de $2020^{12}$ e, consequentemente, a todo um campo

11 Com roteiro e reportagem de Ligia Guimarães, o documentário está disponível no Youtube sob o título "As histórias por trás de recorde de mortes pela polícia em plena pandemia": <https://youtu.be/YtfXZAdI8dU>. O vídeo se encontra também na matéria "'Mãe, fica tranquila, a gente tá dentro de casa': as famílias destruídas pela violência policial em plena pandemia", de 13 de janeiro de 2021, assinada por Ligia Guimarães e Claire Press: $<$ https://www.bbc.com/portuguese/brasil-55582716>.

12 Minneapolis em chamas: a cena do homem negro sendo estrangulado por um policial foi o estopim para uma onda de atos antirracistas, um grito pelo direito à respiração. O apelo "I can't breathe" ("Eu não consigo respirar"), repetido várias vezes por Eric Garner (2014) e George Floyd (2020), transformou-se em um slogan da campanha Black Lives Matter. Fundado em 2013 sob a influência de diferentes correntes pró-direitos civis dos séculos $\mathrm{XX}$ e XXI, o movimento coordena protestos massivos contra a violência racialmente motivada (sobretudo a policial). Tornou-se mundialmente conhecido devido à difusão da hashtag \#BlackLivesMatter no espaço da (ciber)militância. No Brasil, sua circulação em inglês coexiste com duas traduções: "vidas negras importam" e "a(s) vida(s) dos negros importa $(\mathrm{m})$ ". Enquanto um acontecimento discursivo, a fórmula ganhou uma série de variações, tanto estritamente linguageiras (como o enunciador coletivizado em "nossas vidas importam"), quanto iconográficas (como as cores da causa LGBTQIA+). Não exploraremos o fato de que o mesmo enunciado foi retomado, deslocado, invertido etc. por formações discursivas e posições sujeitos antagônicas. 
de discussões sobre os efeitos atuais da necropolítica, do necropoder e das articulações sombrias entre massacre e burocracia. No entanto, ele ganha outro matiz no documentário devido ao acréscimo de um sintagma preposicional e de um ponto de interrogação, o que promove uma atualização dos sentidos postos em funcionamento antes e em outro lugar. $\mathrm{O}$ contraste entre o vermelho e o negro enfatiza a palavra "Brasil" e a interrogativa, diferenciando-as dos demais elementos, o que discursiviza uma dúvida atribuída à injunção do fotografado com o local a que lhe foi naturalizado como evidente para estar, morar e morrer.

Ao analisar as estatísticas que apontam a relação entre a moradia na comunidade, educação, desemprego e preconceito, Nascimento afirma:

Estes algarismos revelam que, para quase cada dois e meio habitantes do Rio, um é negro; porém para cada habitante branco das favelas, quase dois e meio são negros. Em outras palavras: os negros compõem menos da metade da população total da cidade, mas a proporção que ocupam nas favelas alcança mais do dobro da cifra apresentada pelos brancos. Assim se caracteriza uma indiscutível segregação habitacional. (NASCIMENTO, 2016, p. 100).

Tal dado é importante para racializar o debate da violência de Estado, bem como compreender o processo de naturalização dos sentidos de quem mora na comunidade e quem deve ser alvo do controle e da violência. Evidenciando essa naturalização dos riscos de morrer que atravessa a combinação entre raça, classe e território, a emergência da fórmula "A vida dos negros importa no Brasil?" nada tem a ver, no documentário, com a posição reacionária que absorve e nega a luta antirracista através de um apagamento (progressivo) de sua especificidade, tal como frequentemente ocorre na universalização "todas as vidas importam". ${ }^{13}$

As variações simbólicas em foco nessa imagem de abertura tampouco são insignificantes. A transformação da assertiva em um problema pode, no limite, implicar paráfrases negativas do tipo "a vida dos negros não importa no Brasil" ou "a vida dos negros importa lá, mas não aqui".

Asfixia. Quadros da violência policial logo sobrevêm à tela de abertura. Ainda que inevitavelmente se assemelhem à imagem do assassinato de George Floyd, tais flagrantes não provocaram uma 13 Cf. "Vidas importam e a falsa simetria: o discurso em movimentos sociais", de Carvalho e Sargentini (2020). 
comoção comparável à do caso estadunidense. Sobreposta às imagens de violência, uma voz em over (d)enuncia:

No Brasil, é fácil encontrar, em vídeos, inumeráveis flagrantes de violência policial. Embora capturados pelas câmeras, poucos casos geram comoção nacional, muito menos viram assunto nas manchetes internacionais. Em um ano em que o grito "Vidas negras importam" varreu o mundo, a BBC foi investigar por que a polícia brasileira é uma das que mais matam e por que os negros são os que mais morrem. Em 2020, o Brasil, principalmente na periferia das grandes cidades, viveu uma crise dupla: além de enfrentar a pandemia do novo coronavírus, que tirou a vida de mais 170 mil pessoas até dezembro, o país registrou recordes no número de mortes pela polícia. O que se viu foi um contrassenso: mesmo com menos pessoas circulando nas ruas em meio ao isolamento social, foram 3.181 mortes cometidas por policiais em intervenções, 6\% a mais do que o mesmo período de 2019. (BBC, 2021 [transcrição nossa]).

Fazendo remissão à fórmula "vidas negras importam", o documentário ressalta a banalização da violência sistemática contra a população negra e periférica do país. Isso se deve a uma espécie de contágio (um curto-circuito) entre os valores semânticos de importar e comover em uma determinada formação discursiva (HAROCHE; HENRY; PÊCHEUX, [1971] 2007), de maneira que tal efeito metafórico (PÊCHEUX, [1969] 1997) seria impossível se um certo funcionamento humanista da denúncia já não estivesse em jogo. ${ }^{14}$ Interessante notar ainda que o elo entre a "pouca comoção" e a "dupla crise" (repressão e pandemia) não está demarcado no intradiscurso, mas é induzido pelas conexões interfrásticas, o que implica a criação de um nexo causal entre elementos bastante heterogêneos. Um possível rearranjo dessa construção midiática seria: "apesar de o grito 'vidas negras importam' ecoar em todo o mundo e os assassinatos cometidos pela polícia brasileira terem aumentado exponencialmente durante a pandemia, a morte de pessoas negras no Brasil gera pouca comoção, fato que não só parece prolongar a violência policial, mas também permite 'questionar' o grito do movimento antirracista".

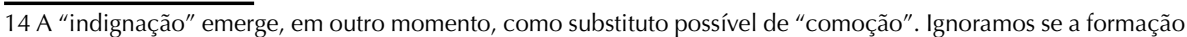
discursiva dispõe tais termos somente em relações de equivalência (comoção = indignação) ou se os hierarquiza, como "a morte de negros não comove, [logo] não causa indignação". 
Na direção de sentidos estabelecida por essa paráfrase, um dos entrevistados (um defensor público) afirma, por exemplo, que a violência e a letalidade policiais se incorporam "ao cotidiano das pessoas", surtindo uma "anestesia da sociedade". Para ele, a morte de civis nessa situação só comove quando é muito difícil ou impossível culpabilizar a própria vítima, como no caso do assassinato de uma criança que brincava dentro de casa. Salvo exceção, a vida dos negros não importaria no Brasil. Sob o signo do terror, a anestesia e a asfixia se combinam, sufocando tudo aquilo que resiste a essa política de extermínio.

Num remoer de falas e vozes, o documentário tenta se contrapor à atual anestesia/asfixia, entrelaçando os fios de dois mundos diversos, incomensuráveis. Por um lado, apresenta-se uma lista de "coisas-a-saber" transmissíveis através de números, dados e estatísticas sobre a violência. O universo calculável do terror ganha forma em dizeres autorizados ou na própria voz em over que costura os entornos da narrativa documental. Por outro, somos expostos ao universo incontável (portanto, inestimável) dos afetos. Nele, ouvimos as vozes enlutadas de três mães cujos filhos foram assassinados em operações policiais. ${ }^{15}$

O mais novo deles, João Pedro Matos Pinto, foi morto aos 14 anos. ${ }^{16} \mathrm{O}$ menino brincava dentro da casa de seu tio em São Gonçalo, quando esta foi invadida pela polícia e alvejada por aproximadamente 80 tiros de grosso calibre, uma semana antes da morte de George Floyd.

Nas tramas da discursividade do documentário, a indignação coletiva diante do caso João Pedro tornou a sobrevivência dos habitantes das favelas cariocas menos difícil, pois provocou a suspensão das operações policiais durante a pandemia.

Oprimidos entre as operações policiais e a pandemia, sobreviver estava cada vez mais difícil pros moradores das favelas cariocas em 2020. Mesmo no período de isolamento social até abril, o número de mortos pela polícia no estado superava em 15\% o de 2019 até a morte de um adolescente: João Pedro, assassinado dentro de casa durante uma operação policial em maio. A morte do menino causou tanta indignação que 18 dias depois do assassinato,

$15 \mathrm{~A}$ figura das mães enlutadas não é casual, mas paradigmática no combate à política de morte empregada pelo Estado. Basta rememorarmos o lugar que elas exerceram nos processos de denúncia e apuração dos crimes das ditaduras latino-americanas ou, mais recentemente, dos crimes do Estado na era das chacinas.

16 Há uma página "Caso João Pedro" na Wikipédia: <https://pt.wikipedia.org/wiki/Caso_Jo\%C3\%A3o_Pedro>. Uma rede de memória se constrói na seção "ver também", em que o caso faz remissão a outros verbetes ligados à necropolítica, como a "Violência policial no Brasil"; a "Morte de George Floyd"; o "Caso menino Miguel" (morte de criança negra que ocorreu no mês seguinte) e o "Assassinato de João Alberto Freitas", asfixiado dentro de um supermercado da rede Carrefour. 
o Supremo Tribunal Federal anunciou a paralização de todas as operações policiais durante a pandemia. Nunca antes uma proibição do tipo havia sido aplicada em todas as favelas do Rio. (BBC, 2021 [transcrição nossa]).

Emaranhando o que é dado a conhecer e o que é dado a ver, sentir e perceber ${ }^{17}$, o documentário adiciona mais esse elemento (o assassinato de jovens negros) a uma intricada relação proporcional entre comoção e violência: "mais violência, menos comoção" / "mais comoção, menos violência". Os termos colocados em cena compõe uma rede de conexões causais, ainda que tais nexos sejam incertos: ou bem a "anestesia da sociedade" é efeito do aumento da violência policial, porém a comoção coletiva causada pela morte de crianças e adolescentes reduz os riscos da crise dupla que oprime os moradores das periferias; ou bem essa "anestesia" provoca o aumento da violência e da letalidade policiais, por isso a comoção reduz os riscos da crise dupla.

Se o discurso sobre a política de extermínio ganha uma forma relativamente estável no roteiro do documentário, os testemunhos das mães e de outros moradores dão margem ao aparecimento de outros dizeres e efeitos de sentido. Nesses casos, a pandemia é relacionada ou comparada à violência policial, como na fala de uma das mães enlutadas: "Preferia hoje que meu filho tivesse pegado um COVID-19 do que ter morrido da forma que ele morreu" (BBC, 2021 [transcrição nossa]). No testemunho da mãe de João Pedro, ela enuncia:

Foi algo assim muito surreal, porque você fica em casa cumprindo a quarentena, com medo dos seus filhos contraírem o vírus que tá aí no mundo e acaba seu filho sendo morto por um vírus bem pior, que é o vírus do Estado que mata. (BBC, 2021 [transcrição nossa]).

Na materialidade da língua, a injunção da história e a luta de vozes dos que vivem na comunidade em diferença radical com o Estado que mata alguns (não todos) naturaliza efeitos sobre aqueles que podem e devem ser mortos (SOUSA, 2020). O dizer da mãe marca esse jogo a partir de um dentro e fora de casa, que implica dois movimentos: i. "fica

17 Para Vladimir Safatle $(2015$, n.p.), o campo da reflexão política diz respeito, sobretudo, à maneira como somos afetados. Uma das questões fundamentais do poder é como organizar o campo do visível, do sensível e do perceptível, levando à problemática da comoção. O autor menciona o choque mundial causado por uma imagem: o corpo de Alan Kurdi (criança de apenas três anos que morreu afogada em uma praia da Turquia): "todos nós vimos como um dos grandes fatos desse ano [2015] foi a simples veiculação de uma foto: [a] foto trágica de um menino sírio morto numa tentativa de seus pais fugirem da Síria numa situação de guerra. [...] Graças à circulação de uma foto que uma política criminosa de bloqueio de refugiados em situação de vida e morte teve que ser momentaneamente suspensa". 
em casa" como evidência da proteção, reserva e cuidado com a saúde que garantiria continuar vivo em tempos de isolamento social, já que "o vírus que tá aí no mundo" mata; e ii. está sedimentado nas formações imaginárias que permanecer em casa, dito por uma mãe, é sinônimo de que os perigos de todas as ordens permanecem do lado de fora, ou seja, a presença de uma mãe cuidaria e conseguiria proteger suas crias. Mas com "o Estado que mata" tal evidência se dissolve e dá lugar ao horror.

"Acaba seu filho sendo morto", essa é a sentença que se fecha sob o efeito de algo "bem pior que o vírus", já que se trata do "vírus do Estado que mata", algo que se regularizou pela historicidade nacional em diferentes momentos e de diversas formas.

Em outro trabalho, foi possível investigar os efeitos de sentidos sobre a morte de crianças executadas pelo Estado nas comunidades do Rio de Janeiro, contornando os sentidos de horror dados por morrer a caminho ou na volta da escola, em casa ou no ambiente educacional (SOUSA; NAGEM, 2021 [no prelo]). A série de mortes e relatos sobre elas indicia o mecanismo ideológico na produção de evidências sobre a autorização do Estado em violentar, executar e assassinar periféricos, prática perversa que dá notícias de "uma doença crônica".

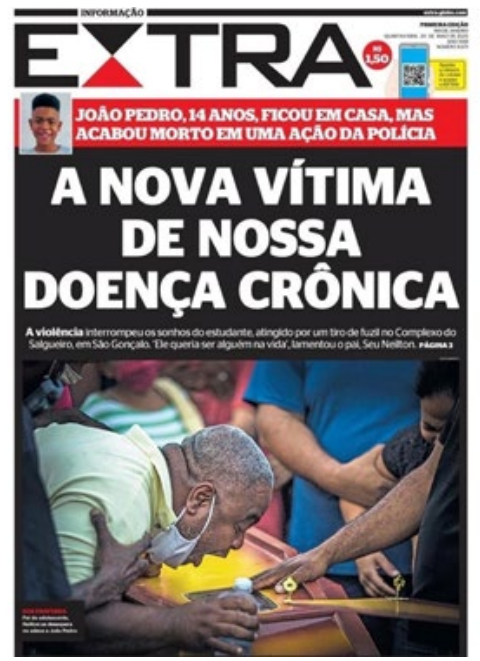

Figura 3: capa do jornal Extra (20 de maio de 2020).

Ainda sobre a morte de João Pedro, os dizeres anteriores, exteriores e independentes ao vídeo circularam nas diversas mídias. Na manchete acima, "A nova vítima da nossa doença crônica", está posto em tensão 
e em divisão os sentidos de/sobre o novo e o velho. "Nova vítima" diante de uma velha "doença": não se trata de um novo vírus, mas de uma doença crônica, o que remete à tensão histórica dos sentidos construídos e regularizados desde a escravização dos africanos no território nacional, prática que sustenta o racismo estrutural e as formas de violência repetidas pelo Estado. Duas imagens litigiam e apontam a contradição de um antes e um depois: o menino sorrindo acima e o pai gritando algo diante do filho morto abaixo. Ambas inscrevem e marcam duas temporalidades diferentes - um antes e um depois da ação policial - que se encontram na formulação "a violência interrompeu os sonhos do estudante". Vale destacar que tem sido uma regularidade a nomeação de que a criança ou o jovem morto são estudantes, no caso estudante com sonhos que "queria ser alguém na vida"; o que atualiza, pelo efeito da memória discursiva, o que é considerado e legitimado como um bem socialmente valorizado: a educação.

No meio da história do estudante, o "tiro de fuzil", mas não apenas ele. As comunidades periféricas têm se organizado regularmente em formas de reclamação de direitos e denúncia do extermínio: narrativas se erguem e constroem a partir de cada morte, relatos e testemunhos passam a ganhar circulação dentro e fora das redes, modos de elaborar o luto se avolumam e mecanismos de responsabilização do Estado têm sido acionados. Os sentidos se movem como no poema de Maya Angelou: "Você pode me fuzilar com/ suas palavras/ Você pode me cortar com seus olhos,/ Você pode me matar com seu ódio,/ Mas ainda, como o ar, eu vou me levantar (...)" ${ }^{18}$

\section{REFERÊNCIAS}

ALTHUSSER, Louis. Ideologia e aparelhos ideológicos do Estado: notas para uma investigação. Lisboa: Presença/ Martins Fontes, 1992.

BBC NEWS. "As histórias por trás de recorde de mortes pela polícia em plena pandemia". 2021. Disponível em: <https://youtu.be/YtfXZAdI8dU>. Acesso 17 mai. 2021.

CARVALHO, Ingrid Cunha; SARGENTINI, Vanice. Vidas importam e a falsa simetria: o discurso em movimentos sociais. Humanidades \& inovação: análise do discurso: o que é e como se faz?, v. 7, n. 24, p. 187-197, 2020.

CASTRO, Edgardo. Vocabulário de Foucault: um percurso pelos seus temas, conceitos e autores. Belo Horizonte: Autêntica, 2009.

18 O poema "Ainda assim eu me levanto", pode ser lido na íntegra na seguinte página: <https://www.revistapazes. com/ainda-assim-me-levanto-maya-angelou/>. 
CHAVES, Tyara Veriato. Entre a escrita e o olhar: uma poética da violência. Tese (Doutorado em Linguística). Campinas: Unicamp, 2020.

DELEUZE, Gilles. Foucault. São Paulo: Brasiliense, 2005.

FOUCAULT, Michel. Em defesa da sociedade: curso no Collège de France. São Paulo: Martins Fontes, 1999.

Histoire de la sexualité: la volonté de savoir. Paris : Gallimard, 1984.

Vigiar e punir. 37 ed. Petrópolis: Vozes, 2009.

FURTADO, Rafael Nogueira; CAMILO, Juliana Aparecida de Oliveira. O conceito de biopoder no pensamento de Michel Foucault. Revista subjetividades, v. 16, n. 3, p. 3444, 2016.

GARCIA, Dantielli Assumpção; SOUSA, Lucília Maria Abrahão. "Somos todxs Cláudia": A legitimação da violência pelo Estado. Linguagem em discurso, v. 15, n. 1, p. 47-59, 2015.

HAROCHE, Claudine; HENRY, Paul ; PÊCHEUX, Michel. A semântica e o corte saussuriano: língua, linguagem, discurso. In: BARONAS, Roberto Leiser. Análise do discurso: apontamentos para uma história da noção-conceito de formação discursiva. São Carlos: Pedro \& João Editores, 2007. p. 13-32.

MBEMBE, Achille. O direito universal à respiração [2020a]. Disponível em: <https:// www.n-1edicoes.org/textos/53>. Acesso em 15 mar. 2021.

O racismo antinegro funciona da mesma maneira que um vírus [2020b]. Disponível em: <https://www.n-1edicoes.org/textos/34>. Acesso em 15 mar. 2021.

. Necropolítica: biopoder, soberania, estado de exceção, política da morte. São Paulo: n-1 edições, 2018.

MODESTO, Rogério. "Você matou meu filho" e outros gritos: um estudo das formas da denúncia. Tese (Doutorado em Linguística). Campinas: Unicamp, 2018.

MONTAG, Warren. "The Soul is the Prison of the Body": Althusser and Foucault, 19701975. Yale French Studies, n. 88, p. 53-77, 1995.

NASCIMENTO, A. O genocídio do negro brasileiro - processo de um racismo mascarado. São Paulo, Perspectiva, 2016.

PÊCHEUX, Michel. Análise automático do discurso (AAD-69). Tradução de Eni Pulcinelli Orlandi. In: GADET, Françoise; HAK, Tony. Por uma análise automática do discurso: uma introdução a obra de Michel Pêcheux. Ed. Campinas: UNICAMP, 1997.

O discurso: estrutura ou acontecimento? Campinas: Pontes, 2012.

SAFATLE, Vladimir. Por um colapso do indivíduo e de seus afetos. 2015. Disponível em: 
<https://www.youtube.com/watch?v=DKLIg6g6pSg>. Acesso 29 mar. 2021.

SEMPRÚN, Jorge. A escrita ou a vida. São Paulo, Companhia das Letras, 1995.

SOUSA, Lucília Maria Abrahão e. Almanaque de fragmentos: ecos do século XIX. Campinas, Pontes, 2020.

SOUSA, Lucília Maria Abrahão; NAGEM, Glaucia. Nada foi o bastante para impedir efeitos do assassinato de crianças no Rio de Janeiro. Stylus, [no prelo].

SPIVAK, Gayatri Chakravorty. Pode o subalterno falar? Belo Horizonte: UFMG, 2014.

RECEBIDO EM: 24/05/2021

ACEITE EM: 09/06/2021 